\title{
Root canal sealers: An review
}

\author{
Preeti Mishra $^{1, *}$, Sachin Gupta ${ }^{2}$, Vineeta Nikhil ${ }^{3}$, Shikha Jaiswal ${ }^{4}$, Shalya Raj ${ }^{5}$ \\ ${ }^{1}$ Lecturer, ${ }^{2,4}$ Professor, ${ }^{3}$ Professor \& HOD, ${ }^{5}$ Reader, Dept. of Conservative Dentistry \& Endodontics, Subharti Dental College, \\ Swami Vivekanand Subharti University, Meerut, Uttar Pradesh, India
}

*Corresponding Author:

Email: preeti.prajesh@gmail.com

\begin{abstract}
The main function of the sealer is to fill the gaps between the core material and the walls of the root canal. A hermetic seal cannot be obtained without the use of a sealer which forms a fluid tight seal and barrier between the dentin and core material apically, laterally and coronally. All sealers are required to possess certain physical and biological properties. These properties include biocompatibility, strength, sealing ability, adequate working and setting time, flow, solubility and various other characteristics. However, no sealer has been shown to be totally satisfactory for clinical use. This article review the ideal properties, functions, classification and methods of application of sealers for better clinical understanding.
\end{abstract}

Keywords: Hermetic seal, Flow, Root canal sealers, Sealing ability.

\section{Introduction}

One of the important objectives of endodontic therapy is obturation of the prepared root canal system with an inert, dimensionally stable and biologically compatible material. The obturation should provide a three dimensional fluid tight seal and prevent the passage of microorganism, their toxin, and tissue fluids from and into the root canal system.

Gutta-percha is universally accepted as the "Gold standard" for the obturating materials. It is non toxic, biocompatible, thermoplastic, retreatable but it presents no adhesiveness to tooth structure and thus it requires a sealer to provide a seal at the canal gutta-percha interface.

The endodontic literature is rich in articles which suggest that conventional gutta-percha alone is not enough to produce and ensure three dimensional seal of the root canal system. Despite the numerous obturating materials and techniques employed, the sealer is an extremely important component of the root canal obturation in order to achieve three-dimensional sealing of the canal space. The sealer has as much or more importance than the core material in providing a successful clinical outcome.

\section{Functions of a sealer}

1. Sealer as Cement (luting/ binding): Sealers act as binding agent for gutta percha cones in lateral condensation obturation technique and also serves to bind the gutta percha to dentinal wall.

2. Sealer as Filler: Sealers are used to fill the gap between the core material and wall of the root canal, between the individual cone, root canal irregularities and the inaccessible areas of the root canal.

3. Bioactivity: Sealers might influence the host response by actively interacting with the local tissue environment. Calcium hydroxide and MTA based sealers can be considered as bioactive sealers with bioactivity.

4. Sealer as an Antibacterial agent: Sealers should be able to control or restrict bacterial growth. Zinc oxide eugenol, Calcium hydroxide and Calcium silicate based sealers have significant antibacterial properties.

5. Sealer as a Lubricant: When used with solid/semisolid obturation materials, sealers act as a lubricant thereby aiding in easy seating of obturation material in the apical area.

6. Sealers may also act as a marker for root resorption, accessory canals root fractures and other spaces into which the main core material may not penetrate, thereby making their clinical or radiographic determination easy.

\section{Classification of root canal sealers}

Various sealers according to their primary constituent or structure are:

\section{A. Zinc Oxide Eugenol Sealers}

1. Rickert's sealer / Kerr's Pulp Canal Sealer (Kerr manufacturing Co.)

2. ProcoSol (Star dental, Conshohocken, PA)

3. Roth's 801 sealer / Grossman's sealer / U/P Root Canal Sealer (Sultan, USA)

4. TubliSeal (Sybron Endo / Kerr; Orange, Calif.)

5. Wach's Sealer / Sealex Extra (Sultan Chemists/ Balas Dental, Chicago, IL, 60602)

6. Fill canal sealer

7. Intrafill (SS White, Brazil)

8. Sultan

9. Medicated Canal Sealer, MCS (Medidenta, Woodside, N.Y.)

10. Canals (Syowa Yakuhin, Japan)

B. Non Eugenol Zinc Oxide Sealers

1. Nogenol (G-C America, Alsip, III, Japan)

2. Canals-N (Syowa Yakuhin, Japan) 


\section{Calcium Hydroxide Sealers}

1. CRCS/ Calciobiotic root canal sealer (Hygienic corp., USA)

2. Apexit (Ivoclar Vivadent, Schaan, Lichtenstein)

3. Sealapex (Kerr manufacturing Co.)

4. Acroseal (Septodont, France)

5. LIFE (Sybron Endo/Kerr; Orange, Calif)

6. Vitapex (NEO Dental, Japan)

7. Dentalis (NEO Dental, Japan)

8. Sealer 26 (Dentsply, Petropolis, Brazil)

9. $\mathrm{CH} 61$

D. Glass Ionomer Sealers

1. Ketac Endo (3M ESPE, Seefeld, Germany)

2. Ketac Cem

3. Endion (VOCO, Germany)

E. Gutta Percha Sealers / Chloroform based Sealers

1. Chloropercha (Moyco, Union Broach, York, PA)

2. Kloroperka $\mathrm{N}-\varnothing(\mathrm{N}-\varnothing$ Therapeutics, Oslo, Norway)

3. Rosin chloroform

F. Sealers Containing Formaldehyde

1. Endomethasone

2. N2/ RC-2B/ Sargenti paste (Indrag- Agsa, Bologna, Italy)

3. Riebler's paste (Amubarut, Germany)

4. SPAD

G. Polymers

1. Resin based sealers

Epoxy resin sealers

a. AH 26 / Thermaseal (De Trey, Zurich, Switzerland / Caulk, Dentsply)

b. AH Plus/ Thermaseal Plus / Topseal (Caulk, Dentsply)

Polyketone based sealers

a. Diaket (ESPE, Seefeld, Oberbayern, Germany)

Methacrylate resin- based sealers

a. EndoREZ (Ultradent, South Jordan, UT)

b. Epiphany (Pentron, Wallingford, CT)

c. InnoEndo (Heraeus- Kulzer, Armonk, NY )

2. Silicone based sealers

Endofill (Dentsply, Latin America, Brazil)

RoekoSeal (Roeko, Lengenau, Germany)

Guttaflow (Coltene Whaledent)

H. Polycarboxylate cements - as sealers

I. Cyanoacrylate Cements - as sealers

J. Titanium oxide based sealer

K. Pastes used as a sole filling material

L. Calcium -silicate based sealers

1. iRoot-SP

2. MTA-Fillapex(Angelus)

3. ProRoot Endo sealer(Dentsply)

4. CPM sealer (Egeo-Argentira)

5. MTA-Obtura(Angelus)

6. F-doped MTA

7. MTAS experimental sealer

M. Experimental Sealers
1. Resin formulations

1. Bis-GMA

2. Pit and Fissure sealants

3. Isopropyl Cyanoacrylate

4. Barrier (Polyamide varnish)

5. Dentin bonding agents

6. Composite resin with a bonding agent.

7. RC sealer

8. Adseal

9. Metaseal

10. Realseal

11. CZ-S2000

2. Calcium phosphate cement sealers

1. Calcium phosphate cements (CPC)

2. Apatite sealers (G-5, G-6, Apatite root sealer)

3. Bioseal (hydroxyapatite sealer containing zinc oxide eugenol)

4. Hydroxyapatite sealer (Cross linked collagen mixed) melted by laser

Properties and requirements for an ideal sealer (ADA specified No. 57)

Grossman listed 11 requirements and characteristics of a good root canal sealer.

1. It should be tacky when mixed to provide good adhesion to the canal wall when set.

2. It should develop a hermetic seal.

3. It should be radiopaque so that it can be visualized in the radiograph.

4. The particles of powder should be very fine so that they can mix easily with the liquid.

5. It should not shrink upon setting.

6. It should not stain tooth structure.

7. It should be bacteriostatic or at least not encourage bacterial growth.

8. It should set slowly.

9. It should be insoluble in tissue fluids.

10. It should be tissue tolerant, that is, nonirritating to periradicular tissue.

11. It should be soluble in a common solvent, if necessary to remove the root canal filling.

Few other requirements that can be added to Grossman's 11 basic requirements are:

12. It should not provoke an immune response in periradicular tissue.

13. It should be neither mutagenic nor carcinogenic.

14. It should be capable of bonding to dentin or guttapercha / core obturation material.

\section{Requirement 1}

It can be said that only polycarboxylates and glass ionomers based sealers satisfy requirement no. 1, i.e good adhesion to dentin. Newer adhesives are being tested at this time and some appear promising. Kataoka et al $(2000)^{1}$ concluded that using bonding agents within the root canal system enhanced the shear bond strength of the root canal sealers to root dentine. However some 
studies have shown that penetration of endodontic sealers into dentinal tubules when smear layer was removed was not associated with higher bond strength (Saleh IM et al 2003). ${ }^{2}$

\section{Requirement 2}

As far as requirement No. 2, the hermetic seal, is concerned; an ideal root canal sealer should have low viscosity and good wetting properties to flow easily into the anatomic irregularities, accessory canals and multiple apical foramina while filling the space between guttapercha cones and surface of the root canal. Sealing ability has been usually evaluated through micro leakage or bond strength testing. Mirjana V, Nevenka T (2010) ${ }^{3}$ reported that Gutta Flow filling material has a strong sealing ability and excellent adhesion to dentinal walls and gutta-percha cones. Ketac-Endo showed excellent bond to dentin with a slightly weaker adhesion capacity to the gutta-percha cones in comparison to Gutta Flow. Pawar SS et al (2014) ${ }^{4}$ evaluated and compared the micro leakage of three sealers; Endosequence Bioceramic (BC) sealer, AH Plus and Epiphany. Micro leakage was evaluated using dye penetration method. They concluded that newly introduced BC sealer and Epiphany sealer sealed the root canal better compared to AH Plus Sealer.

\section{Requirement 3}

Radiopacity, requirement No. 3 , is provided by salts of heavy metals and a halogen: lead, silver, barium, bismuth, or iodine. It is difficult to compare radiographically the quality of root filling when such a variance exists in radiopacifiers. The type and thickness of root canal sealers can influence the radiopacity of root fillings (Baksi BG et al 2007). ${ }^{5}$ ISO 6876/ 2001 established that root canal sealer should be at least as radiopaque as $3 \mathrm{~mm}$ aluminium ${ }^{6}$. But excessive radiopacity of the material has not been mentioned by ISO standardization. Thakur S $2013^{7}$ found that the radiopacity of $\mathrm{AH}$ Plus was found to be $8.92 \mathrm{~mm} \mathrm{Al}$, which exhibited the highest radiopacity than Roekoseal, Epiphany and Kerr PCS. Radiopacity properties of AHPlus sealer was contributed to zirconium oxide and iron oxide content. Epiphany sealer contains silane treated barium borosilicate glass, barium sulfate and bismuth which provides radiopacity. Kerr PCS includes silver particles to improve the radiopacity. Zirconium dioxide is the radiopaque ingredient for Roekoseal.

\section{Requirement 4}

Fine particle size which as in Requirement No. 4, sealer is applied in the least film thickness which is favorable for minimizing micro leakage. An adequate film thickness is an important property of an endodontic sealer, when used in combination with gutta-percha, to eventually fill minimal voids between gutta-percha and the root canal walls, ensuring a hermetic threedimensional root canal obturation. Testarelli L et al
$2003)^{8}$ evaluated the film thickness of the following five root canal sealers: RSA, Rocanal R4, N2, Bioseal and Acroseal. They concluded that RSA and Acroseal showed the best results (a statistically significant difference was noted among these sealers and the others). On the other hand Bioseal and (partially) N2 showed values compatible with a valid clinical use, while Rocanal R4 showed values higher than minimum standard values allowed by ANSA/ADA spec. no. 57.

\section{Requirement 5}

Most root canal sealers shrink or expand as a result of setting. Dimensional change studies are important to show the potential of sealers to provide desired hermetic seal and bonding core materials to the dentinal walls. ISO standards recommend a maximum shrinkage of $1 \%$ or expansion of $0.1 \%$ of the measured sample length for root canal sealers. During polymerization of resin sealers there is the shrinkage stresses created on the root canal walls. There are several factors for the inferior sealing properties of methacrylate resin-based sealers inside root canals. Polymerization shrinkage of the sealer might create gaps along the sealer-dentin interface because of pulling of resin sealer tags out of the tubules during polymerization shrinkage. The partially polymerized sealer when manipulated during compaction of the root filling materials might disrupt the developing bonds between a self-etching primer and radicular dentin. Light-curing the coronal part of the root filling to create a coronal seal might also limit flow of resin sealer. Hydrophilic methacrylate resin-based sealer Epiphany showed the greatest dimensional change with $8 \%$ expansion in accordance with the results of Hammad et al. reported that polymerization shrinkage after setting is a serious problem for resin-based sealers. ${ }^{6}$

\section{Requirement 6}

As per Grossman's requirement no. 6 the sealer should not stain tooth structure however this requirement is evidently being violated by a number of sealers. Marina AM et al $(2015)^{9}$ reported that tooth staining was visually detected for Sealer 26 and might be associated with the formaldehyde released and its interaction with the radiopacifier bismuth oxide. Application of MTA Fillapex in tooth crown resulted in minimal color alteration, while Roth 811 induced severe alteration.

\section{Requirement 7}

Grossman (1980) ${ }^{10}$ investigated the significance of his requirement No. 7, bacteriostatic effect of sealers. After testing root canal cements, he concluded that they all "exerted antimicrobial activity to a varying degree," those containing paraformaldehyde to a greater degree initially. With time, however, this latter activity diminished, so that after 7 to 10 days the formaldehyde cements were no more bactericidal than the other cements. Endodontic sealers that possess both optimum flow ability and antimicrobial ability may assist in 
eliminating microorganisms located in confined areas of root canal (Siqueira JF et al 2000). ${ }^{11}$ Sealers exhibit different antibacterial and physical properties according to their mixing consistencies (Fuss Z et al 2000). ${ }^{12}$

\section{Requirement 8}

As per requirement 8 , sealer should set slowly. Setting time must be long enough to allow placement and adjustment of root filling if necessary (McMichen et al 2003). ${ }^{13}$ However it should be as short as possible because of difficulty in maintaining the dryness of the empty prepared canal. The ANSI/ADA Specification ${ }^{14}$ requires that the setting time of a sealer shall be within $10 \%$ of that stated by the manufacturers. Gabriela A M B et al (2012) ${ }^{15}$ concluded that $\mathrm{AH}$ Plus ${ }^{\circledR}$ and Apexit Plus ${ }^{\circledR}$ are in agreement with ANSI/ADA standards.

\section{Requirement 9}

As per requirement No. 9 sealers should not be soluble in tissue fluids. The root canal sealer should be insoluble or exhibit atleast low solubility so as to achieve the long lasting bacterial tight seal of the root canal. Moreover, sealers should be of low solubility because components leaching from the root canal filling may have undesirable biological effects on the surrounding tissues (Geurtsen \& Leyhausen 1997). ${ }^{16}$

\section{Requirement 10}

The very important requirement No. 10, tissue tolerance, studies have demonstrated that root canal filling materials have some cytotoxic effect and it is advisable that these material should be applied with extreme caution during endodontic therapy (Serper A et al 1998). ${ }^{17}$

\section{Requirement 11}

As per requirement 11 is concerned, the ability to remove the material from the root canal is a prerequisite of endodontic filling materials. The sealers however, may resist attempted removal and as a result, the amount of sealer debris residue on the retreated canal walls is significantly larger than the amount of residual guttapercha (Wilcox et al $1987,{ }^{18}$ Wilcox et al $1989^{19}$ ).

\section{Requirement 12}

As per requirement 12 , the sealer should not provoke an immune response in periradicular tissue but this requirement is not satisfied by many root canal sealers.

\section{Requirement 13}

As per requirement 13 , the sealer should be neither mutagenic nor carcinogenic. It has been reported that eugenol and its metabolites, although suspect, were uniformly negative in a bacterial mutagenicity test; hence the probability that eugenol is a carcinogen is relatively low. (Harnden DG et al 1981) ${ }^{20}$ Formaldehyde, formalin, and paraformaldehyde (N2/RC 2B, Endomethasone sealers), on the other hand, have been reported to be the suspects.

\section{Requirement 14}

As per requirement 14, the sealer should be capable of bonding to dentin or gutta-percha / core obturation material. AH Plus has greater adhesion to root dentin than Epiphany as it is an epoxy resin-based sealer. $\mathrm{AH}$ Plus has better penetration into the micro-irregularities because of its creep capacity and long setting time, which increases the mechanical interlocking between sealer and root dentin and the cohesion of sealer causes Resilon to be more resistant to fracture.

\section{Sealer Placement}

1. A critical component of the obturation procedure is sealer placement. Inadequate sealer placement may result in voids in the root canal filling and permit bacterial microleakage from the canal into the periapical tissues. Excess sealer in the canal space can result in its extrusion beyond the periapical foramen, resulting in a foreign body reaction in the periapical tissue which can prevent or delay healing.

2. Sealer placement is influenced by accessing opening, canal configuration, size to which the canal is instrumented.

\section{Sealer placement techniques ${ }^{10,20-22}$}

Sealer can be placed in the root canal using various techniques

1. File

2. Reamer

3. Absorbent paper point

4. Master cone

5. Lentulospiral

6. An ultrasonic file

7. Pressure injection syringe

8. Bidirectional spiral

\section{Method of placement}

\section{Using broach, absorbent point or reamer}

After the cement is mixed, it is carried into the canal on a sterile, blunt smooth broach, absorbent point, or reamer rotated in reverse. First the walls of the canal are coated with a lateral, rotary motion, carrying the material slowly towards apex. Then with a slow, pumping motion, an effort is made to fill the apical end completely and, at the same time, to expel air which might be trapped in the cement.

\section{Using lentulo plugger}

The sealer may also be carried into the canal by a slowly rotating lentulo plugger. The plugger is inserted with a small amount of cement on it into the root canal without running the engine at first, then the engine is run to coat the canal wall. As the plugger is being withdrawn from the canal, it is pressed slightly against the canal wall. 


\section{Indications}

The lentulo plugger should be used only in reasonably wide canals.

\section{Disadvantages}

Using it in narrow canal may cause its breakage. Also there is the additional risk of carrying a considerable amount of the sealer through the apical foramen by this means, as the sealer is propelled forward by the lentulo plugger.

\section{Using pressure injection syringe ${ }^{10}$}

It was developed by Greenberg and popularized by Krakow and Berk. The pressure syringe provides an effective method of introducing the sealer into the canal. The canal may be filled entirely with sealer without a solid core of gutta- percha or silver cone.

\section{Method of Placement}

The sealer is mixed, loaded in the pressure syringe, and introduced with a fine needle to about $2 \mathrm{~mm}$ from the apical foramen. The sealer is extruded by giving the handle of the syringe a quarter turn. Additional sealer is extruded from the syringe into the canal in stages until the canal is completely filled with sealer.

\section{Indications}

It is particularly useful in filling fine tortuous canal that cannot be negotiated with instruments and in filling some large canals.

\section{Drawbacks}

Excessive extrusion of sealer into the periapical space may occur, causing inflammatory changes in periapical tissue and discomfort to patient.

\section{Using bidirectional spiral}

1. Wu MK et al (2006) ${ }^{23}$ reported that sealer extruded apically in $88 \%$ of roots when gutta-percha cone was used to introduce the sealer and $28 \%$ of roots when bidirectional spiral was used, the canals were obturated with single cone technique using RoekoSeal RSA as sealer.

\section{Master gutta-percha coating technique}

3. The master gutta-percha coating technique is the simplest method among the three methods tested and it requires no additional instruments and procedures.

4. This will also reduce the risk of possible cross infection.

5. Produces the lowest microleakage values; it would be suggested to be used for better results

\section{Conclusion}

However till date, no sealer has been shown to be totally satisfactory for clinical use. All materials recommended for root canal filling have advantages and disadvantages and there is no single stereotype material or technique available so far, that fulfills all the possible requirements. The choice of sealer will depend on the core material and technique of obturation which in turn will depend upon the anatomy of the root canal. The choice of sealer may also be influenced by pre-existing periapical conditions for achieving prognostic healing outcome.

Funding: No funding sources.

Conflict of interest: None declared.

\section{References}

1. Kataoka H, Yoshioka T, Suda H et al. Dentin bonding and sealing ability of a new root canal resin sealer. J Endod 2000;26(4):230-34.

2. Saleh IM, Ruyter IE, Haapasalo MP et al. Adhesion of endodontic sealers: Scanning electron microscopy and energy dispersive spectroscopy. J Endod 2003;29(9):595601.

3. Mirjana Vujaskovic,Nevenka Teodorovic. Analysis of sealing ability of root canal sealers using scanning electronic microscopy technique. Srp Arh Celok Lek 2010;138(11-12):694-98.

4. Pawar SS, Pujar MA, Makandar SD. Evaluation of the apical sealing ability of bioceramic sealer, AH plus \& epiphany: An in vitro study. J Conserv Dent 2014 Nov;17(6):579-82.

5. Baksi BG, Eyuboglu TF, Sen BH et al. The effect of three different sealers on the radiopacity of root fillings in simulated canals. Oral Surg Oral Med Oral Pathol Oral Radiol Endod 2007;103:138-41.

6. International organization for standardization ISO 6876 2001. Dental root sealing materials as quoted by Tanomaru JMG et al. Evaluation of the radiopacity of root canal sealers by digitization of radiographic images. J Appl Oral Sci 2004;12(4).

7. Sandeep Thakur, Mithra N Hegde, and Darshana Devadiga Research Journal of Pharmaceutical, Biological and Chemical Sciences. resin based root canal sealers: an overview. RJPBCS 2013;4(4):1501

8. Testarelli L, Andreasi Bassi M, Gambarini G.In vitro evaluation of five root canal sealers. Minerva Stomatol 2003;52(1-2):19-24.

9. Marina Angelica Marciano, Josette camilleri, Rafael Francisco Lia Mondelli et al. Potential tooth staining due to root canal sealers containing bismuth oxide and formaldehyde. Endo 2015;9(1):39-5.

10. Grossman, LI. J Endod 1976;2:166. In Grossman LI. Endodontic Practice. $10^{\text {th }}$ ed. Lea and Febiger, Philadelphia; 1988:297-302.

11. Siqueira JF, Fraga RC, Garcia PF. Evaluation of sealing ability, $\mathrm{pH}$ and flow rate of three calcium hydroxide based sealers. Endod Dent Traumatol 1995;11:225-28.

12. Fuss Z, Charniaque O, Pilo R et al. Effect of various mixing ratios on antibacterial properties and hardness of endodontic sealers. J Endod 2000;26(9):519-22.

13. McMichen FRS, Pearson G, Rahbaran S et al. A comparative study of selected physical properties of five root-canal sealers. Int Endod J 2003;36:629-35.

14. Al-Awadhi S, Spears R, Gutmann JL et al. Osteoblast viability and apoptosis in the presence of root canal sealers. J Endod 2004;30:527-33.

15. Gabriela Alexandra Marin-Bauza,Yara Teresinha Correa Silvasousa,Carlos Eduardo Saraiva Miranda. Physicochemical properties of endodontic sealers of different bases. J Applied Oral Sci 2012;20(4):455-61. 
16. Geurtsen W, Leinenbach F, Krage T et al. Cytotoxicity of four root canal sealers in permanent 3T3 cells and primary human periodontal ligament fibroblast cultures. Oral Surg Oral Med Oral Path Oral Radiol and Endod 1998;85:5927.

17. Serper A, Ucer O, Oner R et al. Comparative neurotoxic effects of root canal filling materials on rat sciatic nerve. $J$ Endod 1998;24(9):592-94.

18. Wilcox LR, Krell KV, Madison S, Rittman B. Endodontic retreatment: evaluation of gutta-percha and sealer removal and canal reinstrumentation. J Endod 1987;13:453-57.

19. Wilcox LR. Endodontic retreatment: Ultrasonics and chloroform, as the final step in reinstrumentation. J Endod 1989;15:125-28.

20. Harden DG. Tests for carcinogenicity and mutagenicity. Int Endod J 1981; 14:35. In Ingle JI, Bakland LK.

Endodontics. $5^{\text {th }}$ ed. Elsevier; 2006:579-596,652-56.

21. Ruddle CJ. Three-dimensional obturation: the rational and application of warm gutta-percha with vertical condensation. In: Cohen S, Burns RC, editor, Pathways of the pulp. $4^{\text {th }}$ Ed. St Louis: Mosby 2006;11:723-35.

22. Habibah Md Said, Wan Zaripah Wan Bakar, Manal Farea, and Adam Husein The effect of different sealer placement techniques on sealing Ability: An in vitrostudy. J Conserv Dent 2012;15(3):257-60.

23. Wu MK, van der Sluis LWM, Wesselink PR. A 1-year follow- up study on leakage of single- cone fillings with Roeko RSA sealer. Oral Surg Oral Med Oral Pathol Oral Radiol Endod 2006;101:662-67.

How to cite the article: Mishra P., Gupta S., Nikhil V, Jaiswal S., Raj S. Root canal sealers: An review. IP Indian J Conserv Endod 2018;3(3):69-74. 